\title{
Biofuel production: an odyssey from metabolic engineering to fermentation scale-up
}

\author{
Whitney Hollinshead, Lian He and Yinjie J. Tang* \\ Department of Energy, Environmental and Chemical Engineering, Washington University, St. Louis, MO, USA
}

\section{Edited by:}

Aindrila Mukhopadhyay, Lawrence Berkeley National Berkeley, USA

\section{Reviewed by:}

Kesen Ma, University of Waterloo, Canada

Ee-Been Goh, Joint BioEnergy Institute, USA

\section{*Correspondence:}

Yinjie J. Tang, Department of

Energy, Environmental and

Chemical Engineering, Washington

University, One Brookings Dr., St.

Louis, MO 63130, USA

e-mail: yinjie.tang@seas.wustl.edu
Metabolic engineering has developed microbial cell factories that can convert renewable carbon sources into biofuels. Current molecular biology tools can efficiently alter enzyme levels to redirect carbon fluxes toward biofuel production, but low product yield and titer in large bioreactors prevent the fulfillment of cheap biofuels. There are three major roadblocks preventing economical biofuel production. First, carbon fluxes from the substrate dissipate into a complex metabolic network. Besides the desired product, microbial hosts direct carbon flux to synthesize biomass, overflow metabolites, and heterologous enzymes. Second, microbial hosts need to oxidize a large portion of the substrate to generate both ATP and $N A D(P) H$ to power biofuel synthesis. High cell maintenance, triggered by the metabolic burdens from genetic modifications, can significantly affect the ATP supply. Thereby, fermentation of advanced biofuels (such as biodiesel and hydrocarbons) often requires aerobic respiration to resolve the ATP shortage. Third, mass transfer limitations in large bioreactors create heterogeneous growth conditions and micro-environmental fluctuations (such as suboptimal $\mathrm{O}_{2}$ level and $\mathrm{pH}$ ) that induce metabolic stresses and genetic instability. To overcome these limitations, fermentation engineering should merge with systems metabolic engineering. Modern fermentation engineers need to adopt new metabolic flux analysis tools that integrate kinetics, hydrodynamics, and ${ }^{13} \mathrm{C}$-proteomics, to reveal the dynamic physiologies of the microbial host under large bioreactor conditions. Based on metabolic analyses, fermentation engineers may employ rational pathway modifications, synthetic biology circuits, and bioreactor control algorithms to optimize large-scale biofuel production.

Keywords: ATP maintenance, hydrodynamics, metabolic flux analysis, proteomics, synthetic biology

\section{MICROBIAL FACTORIES FOR BIOFUEL PRODUCTION}

Extensive research has been performed on the microbial production of biofuels using renewable feedstocks (Figure 1). Carbohydrates, the major carbon sources for biofuel production, can be obtained from either food crops or lignocellulosic biomass. Glycerol, lactate, acetate, and syngas are also used as feedstocks for biofuel synthesis. Moreover, photo-biorefineries are being developed to turn light energy and $\mathrm{CO}_{2}$ into useful chemicals (Lindberg et al., 2010; Lan and Liao, 2012; Oliver et al., 2013). Recently, the Department of Energy has started initiatives to target methane as a cheap resource for "gas-to-liquids" bioconversion in the hope of surpassing Fischer-Tropsch process for liquid fuel production (Conrado and Gonzalez, 2014). Despite the numerous feedstocks that are proposed for biofuel fermentation, production of cheap biofuel has not yet been realized.

Ethanol fermentation by yeast is the most developed biofuel process, but low combustion energy and high purification costs prevent the wide use of ethanol as an economical fuel. Thereby, researchers have engineered microbes to produce new fuels. Advanced biofuel examples include higher alcohols via the ketoacid and the Ehrlich pathway (Atsumi et al., 2008), terpene-based fuels (e.g., isopentenol) from the mevalonate pathway (Withers et al., 2007), fatty acid ethyl esters (Kalscheuer et al., 2006; Steen et al., 2010) and alkanes from fatty acid biosynthesis pathways (Choi and Lee, 2013). These biofuel pathways have been extensively reviewed (Rude and Schirmer, 2009; Peralta-Yahya et al., 2012). Despite the development of these diverse biofuel producers, it is still challenging to commercialize biofuel processes due to the poor microbial productivity in large bioreactors and the low profit margins of biofuels (Zhang, 2009; Lamonica, 2014). As a result, many biotechnology companies have shifted their focus away from advanced biofuels to products with higher commercial value. This review discusses both the metabolic and bioprocess limitations in the scale-up of these biofuel processes and emphasizes the need to integrate systems biology, synthetic biology, and fermentation engineering to optimize metabolic performance in large bioreactors.

\section{METABOLIC ENGINEERING APPROACHES FOR BIOFUEL SYNTHESIS}

The microbial host's metabolism consists of thousands of chemical reactions that control the carbon and energy [e.g., ATP \& $\mathrm{NAD}(\mathrm{P}) \mathrm{H}]$ metabolism. The desired biosynthetic pathway for advanced biofuels often requires multiple enzymatic steps. Current molecular biology techniques can effectively alter enzyme 


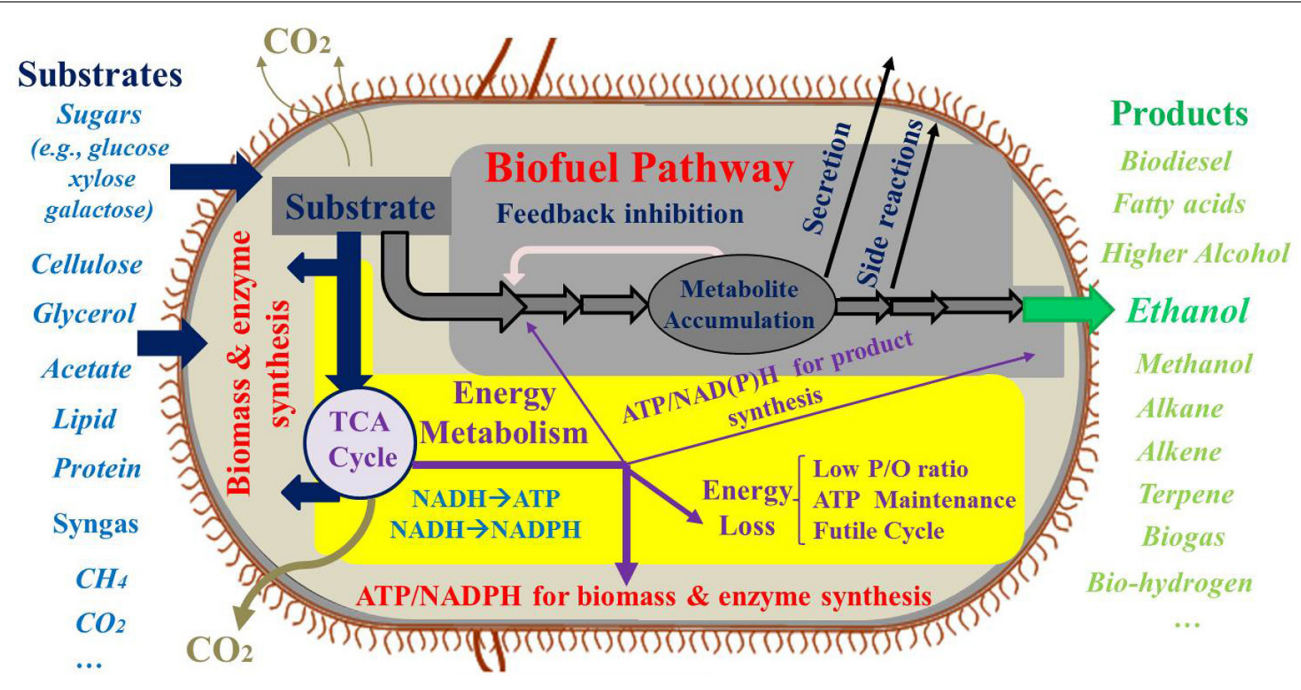

FIGURE 1 | Carbon and energy limitation for biosynthesis.

levels to increase the flux toward biofuel synthesis. Common strategies include choice of plasmids and its copy numbers, promoter engineering, codon optimization, synthetic scaffolds, directed evolution/modification of key enzymes, improvement of ribosome binding sites, and knockout/knockdown of competitive pathways (Dueber et al., 2009; Carneiro et al., 2013; Nowroozi et al., 2014). New genetic techniques, such as RNA Interference, CRISPRs or TALENs, offer new capabilities to edit microbial metabolisms (Pratt and MacRae, 2009; Jiang et al., 2013; Sun and Zhao, 2013).

To improve the carbon flux to the final products, metabolic engineering often applies two strategies. The first strategy is the "push-pull-block," used to increase the flux toward the biofuel synthesis pathway (Atsumi et al., 2010a; Kind et al., 2013). For example, a threonine-overproducing E. coli strain was engineered to produce 1-propanol via the keto-acid pathway by the "push-pull-block" strategy (Choi et al., 2012): (1) "Pull"-introduce a heterologous feedback resistant threonine dehydratase, (2) "Block"-remove competing metabolic pathways, and (3) "Push"-overexpress acetate kinase and other enzymes in the citramalate pathway to increase carbon flux into the propanol pathway. The second metabolic engineering strategy is to design an alternative biosynthesis pathway that can reduce the loss of carbon by unwanted byproducts. For example, a non-oxidative glycolytic cycle in E. coli has been developed to achieve the complete carbon conversion of sugar into acetylCoA (Bogorad et al., 2013). Although these metabolic engineering strategies are effective in increasing the carbon flux toward the desired product, metabolic engineers cannot easily create "biofuel super bugs". Extensive genetic modifications often increase metabolic burdens on the host and thus further interfere with cell growth and product synthesis (Colletti et al., 2011; Poust et al., 2014). For example, high copy number plasmids or strong promoter can place a heavy burden on the cell's growth and negatively affect productivity (Carrier et al., 1998; Jones et al., 2000). Moreover, host cells may incorrectly express or misfold heterologous enzymes, reducing their activities. Low temperature fermentation may be required to ensure the functions of these heterologous enzymes (Chang et al., 2007). In addition, pathway engineering may cause metabolic imbalances and waste product secretions.

An emerging field, synthetic biology, aims to design and construct new biological systems to enhance the capability of engineered microbes (Nielsen et al., 2014). Synthetic biology has been developing genetic circuits that can precisely regulate gene expression in the presence or absence of chemical and environmental inputs (Khalil and Collins, 2010). These synthetic biological devices have been reviewed recently (Way et al., 2014), which include such devices as a toggle switch (two repressors turn each other off), trigger-memory system, and genetic oscillators. Synthetic biology tools have started to be used by metabolic engineers to manipulate fluxes toward biosynthesis pathways at different fermentation stages. For example, a recent study engineered a toggle switch into E. coli that could turn off the TCA cycle and redirect flux toward isopropanol (Soma et al., 2014). Among the synthetic biology tools (Neupert et al., 2008; Topp et al., 2010; Gorochowski et al., 2013), biosensor-regulator systems have particular value for their potential to control a microbial host metabolism according to environmental changes, and thus improve the productivity of microbial hosts (Zhang et al., 2012).

\section{METABOLIC DILEMMA: CARBON YIELD vs. ENERGY EFFICIENCY}

Current research often focuses on the improvement of carbon fluxes toward the final product. However, the high demand of energy and reducing equivalents during biofuel synthesis is another important obstacle. First, polymerization of protein and DNA/RNA requires large amounts of ATP $(39.1 \mathrm{mmol}$ ATP/g protein; $7.4 \mathrm{mmol}$ ATP/g RNA; and $11.0 \mathrm{mmol}$ ATP/g DNA) (Stephanopoulos et al., 1998). Production of biomass, enzymes for biofuel synthesis, plasmids/mRNA, or synthetic scaffolds 
consumes not only carbon building blocks, but also energy molecules. Second, large amounts of ATP need to be consumed to support cell maintenance processes including energy spilling, microbial motility, cell component repair, and re-synthesis of macromolecules (Hoehler and Jorgensen, 2013). Third, synthesis of biofuel molecules needs ATP and NAD $(\mathrm{P}) \mathrm{H}$. For example, fatty acid production requires 7 ATP and 14 NADPH to convert acetylCoA molecules into one fatty acid (Palmitate, C16:0). The carbon oxidation pathways (such as TCA cycle and oxidative pentose phosphate pathway), oxidative phosphorylation, and transhydrogenase reactions are required to generate sufficient NADPH and ATP for fatty acid synthesis (He et al., 2014; Varman et al., 2014).

Theoretically, 38 ATP molecules are produced from one glucose molecule. Among the 38 ATP molecules, glycolysis and TCA pathways only contribute to 4 ATP, and the remaining 34 ATP are obtained from oxidative phosphorylation, assuming the maximum $\mathrm{P} / \mathrm{O}$ ratio $\left(1 \mathrm{NADH} \rightarrow 3\right.$ ATP and $\mathrm{FADH}_{2} \rightarrow 2$ ATP) (Shuler and Kargi, 2002). Under anaerobic conditions, the energy metabolism is inefficient and cells often secrete acetate to overcome the ATP shortage. If the biofuel synthesis requires large amounts of ATP, oxidative phosphorylation becomes a key source for satisfying the ATP demand (i.e., use of aerobic respiration to generate the needed ATP). In addition to the high ATP demand imposed by the biofuel synthesis pathway, metabolic flux analysis studies have revealed that the overexpression of biosynthesis pathways significantly increases ATP maintenance expenditure (Ow et al., 2009), and the metabolic burden in engineered microbial hosts further causes poor respiration efficiency (e.g., P/O ratio = 1.3) (Varma and Palsson, 1994; Sauer and Bailey, 1999). If the hosts suffer from severe ATP limitations, efforts to reduce carbon losses or to increase carbon availability to biofuel synthesis will be futile. In this case, the metabolic bottleneck may shift from carbon limitation to energy limitation (insufficient energy molecules to power biofuel synthesis). Many metabolic engineering approaches to improve carbon efficiency are effective in redirecting carbon fluxes to biofuel in low productivity strains (yield far below theoretical value), but these strategies cannot raise product yields close to stoichiometric predictions if the engineered metabolism is unable to satisfy the overall ATP and $\mathrm{NAD}(\mathrm{P}) \mathrm{H}$ requirements by the microbial hosts. The priorities toward high carbon yield and energy efficiency have to be carefully balanced during strain development of biofuel producers.

\section{SCALE-UP FERMENTATION OBSTACLES: METABOLIC STRESSES UNDER SUBOPTIMAL CULTURE CONDITIONS}

Fermentation engineering emerged in the early 1940s driven by the mass production of penicillin. Since then, engineers have scaled up fermentation of commodity products such as 1,3propanediol (Nakamura and Whited, 2003) and amino acids (Hermann, 2003). Currently, Gevo and Butamax are commercializing isobutanol production from engineered yeast (Nielsen et al., 2014). Industrial isobutanol fermentation is one of the most promising biofuel fermentations as: (1) yeast is a robust industrial host that has a natural tolerance to alcohols; and (2) in situ removal techniques such as gas-stripping have alleviated product toxicity during the fermentation process (Baez et al.,
2011). However, large-scale fermentations of other fuels (such as biodiesels) are still underdeveloped.

Maintaining the optimal growth environments in large bioreactors is difficult. In industrial bioreactors (on the scale of $100 \mathrm{~m}^{3}$ ), the poor mixing/aeration can cause temperature and $\mathrm{pH}$ fluctuations, $\mathrm{O}_{2}$ limitations, substrate/product inhibitions, and accumulations of wastes (such as acetate) (Enfors et al., 2001). The heterogeneous conditions can increase cell stress and ATP maintenance. If gaseous substrates (such as $\mathrm{CO}_{2}$, syngas or $\mathrm{CH}_{4}$ ) are used for fermentation, gas-liquid mass transfer resistances pose another serious challenge as the gaseous substrates must diffuse across the gas-liquid interface (Blanch and Clark, 1997). In addition, large-scale bioreactors (e.g., a fed-batch bubble column reactor) feed the substrate from the top and aeration from the bottom, creating opposite substrate and $\mathrm{O}_{2}$ gradients (i.e., $\mathrm{O}_{2}$ limitation at the top and substrate limitation at the bottom). This has been reported to cause increased production of waste products, such as formate, lactate, and succinate (Bylund et al., 1998, 2000). Moreover, cell factories synthesizing biofuels are subjected to metabolic burdens due to the drainage of both metabolic precursors and energy for the replication of plasmids, and biosynthesis of heterologous enzymes and products (Carneiro et al., 2013). The suboptimal growth conditions in large bioreactors tend to intensify stress responses, induce metabolic shifts, and alter cell genetic stability. Altogether, most of the engineered "super bugs" struggle to move beyond lab settings.

\section{${ }^{13}$ C-MFA: AN INDISPENSABLE TOOL FOR SCALE-UP FERMENTATION ENGINEERING}

Systems biology can characterize biofuel producers and provide guidelines for rational metabolic engineering and optimal fermentations (Figure 2) (Carneiro et al., 2013). "Omics" (transcriptomics, proteomics, and metabolomics) approaches can identify useful mutations, discover gene regulations and enzyme functions, and measure the metabolite pools in response to environmental fluctuations (Pham et al., 2006; Atsumi et al., 2010b; Redding-Johanson et al., 2011). Although genome-wide analyses and computational modeling have provided knowledge for the metabolic engineering of microbial hosts (Park et al., 2008), it is not straightforward to correlate "omics" to actual enzyme functions due to complex post-transcriptional regulations (such as allosteric regulation) (Chubukov et al., 2013). For example, increases in mRNA levels may not lead to a corresponding increase in protein levels, while enzyme levels can remain constant despite frequent changes in carbon fluxes (Gygi et al., 1999). In addition, the existence of isoenzymes and poor enzyme specificity contribute to high metabolome diversity and lead to difficulties in metabolomic studies (Schwab, 2003). To overcome such problems, ${ }^{13} \mathrm{C}$-MFA (metabolic flux analysis) is used to directly measure enzymatic reaction rates. Compared to other omics studies, ${ }^{13} \mathrm{C}$-MFA can provide insights into cell's physiology during large-scale fermentations. ${ }^{13} \mathrm{C}$-MFA uses metabolic reaction stoichiometry and carbon-labeling experiments to precisely estimate metabolite turnover rates (Sauer, 2006; Tang et al., 2009). ${ }^{13} \mathrm{C}$ MFA in combinations with other in silico metabolic models (flux balance analysis) (Edwards et al., 2001; Orth et al., 2010) can pre- 


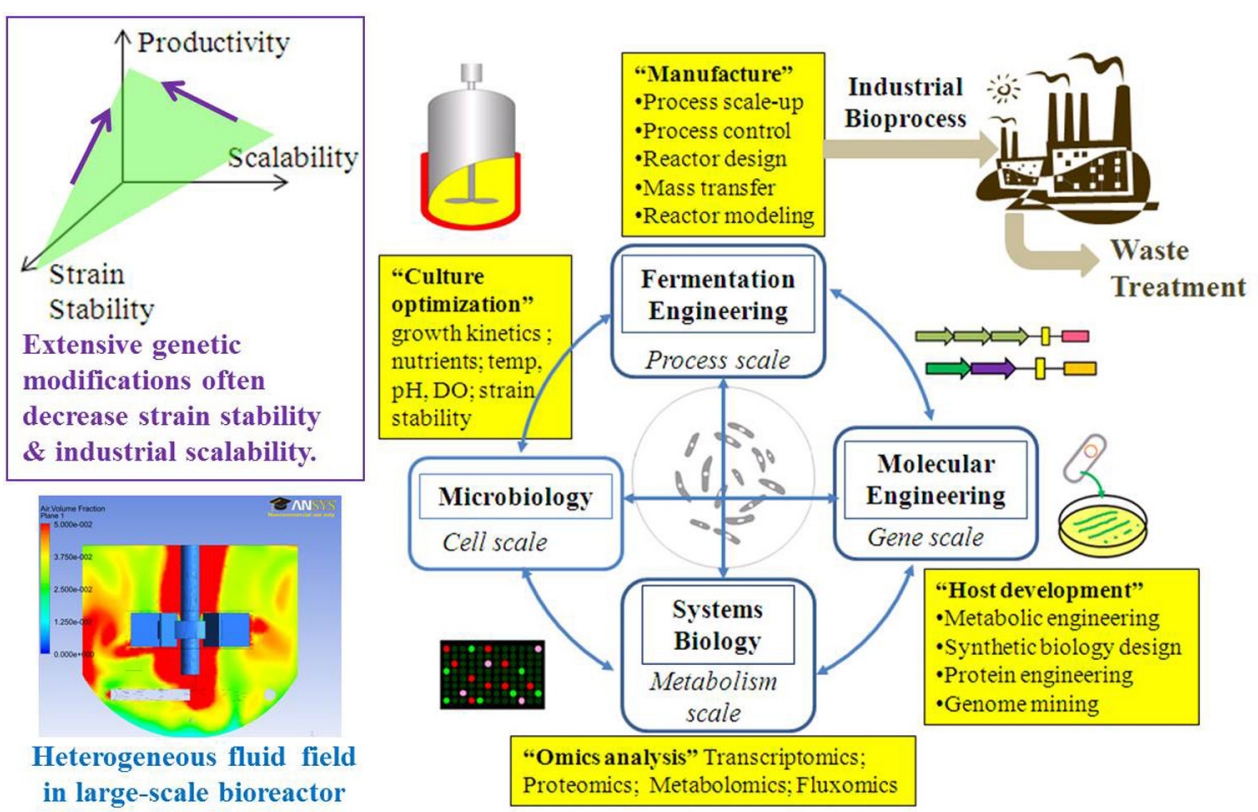

FIGURE 2 | The design-engineering-analysis cycle for scale-up of biofuel fermentation.

dict biosynthesis yield, delineate functional pathways, calculate the actual fluxes throughout the metabolic network, validate the function of genetic circuits, and identify metabolic engineering targets. Integration of flux analysis with transcriptomics and proteomics can provide a comprehensive understanding of the genetic regulations of intracellular activities (Zhang et al., 2010; Yoon et al., 2012; Arakawa and Tomita, 2013; Liu et al., 2013).

During the fermentation process, metabolic shifts and genetic mutations are common, which can create subpopulations in the cultures (biofuel producers vs. mutants after loss of biofuel production). Sauer group proposed a "reporter protein"-based ${ }^{13} \mathrm{C}-\mathrm{MFA}$ to probe the metabolism of subpopulations (Rühl et al., 2011). This reporter protein, synthesized by a particular subgroup, stores the ${ }^{13} \mathrm{C}$-labeling information of that subgroup which allows ${ }^{13} \mathrm{C}$-MFA to identify the different metabolic flux phenotypes. This proof-of-concept approach was tested using engineered E. coli (Shaikh et al., 2008; Rühl et al., 2011). Based on the labeling information from hydrolysates (i.e., amino acids) of the green fluorescent protein (GFP), ${ }^{13} \mathrm{C}-\mathrm{MFA}$ was able to probe the subpopulation metabolism (GFP producers) during E. coli fermentation. Recently, proteomic analysis of ${ }^{13} \mathrm{C}$-peptide labeling has also been developed to assist metabolic flux analysis of heterogeneous microbial systems (Mandy et al., 2014). The "reporter proteomics" associated with a specific time of protein expression or a unique species may decipher subpopulation physiologies and its dynamic changes in microbial consortia. These studies have paved the way to analyze temporal and spatial microbial phenotypes during a large-scale heterogeneous fermentation.

In addition, ${ }^{13} \mathrm{C}$-MFA may integrate with microbial kinetics to reveal the changes of cell metabolism throughout its cultivation process. For example, Sauer group have utilized such a dynamic ${ }^{13} \mathrm{C}-\mathrm{MFA}$ approach in a fed-batch fermentation to monitor the dynamic changes in intracellular fluxes during the different growth stages. Their results revealed that a riboflavin-producing bacterium's physiology shifted from an overflow metabolism to an exclusively maintenance metabolism at the late fermentation stage (Rühl et al., 2010). To determine microbial responses to industrial bioreactor configurations and cultivation heterogeneity due to mass transfer limitations, even more novel ${ }^{13} \mathrm{C}-\mathrm{MFA}$ approaches are required. For example, metabolic flux analysis in combination with hydrodynamics would provide important insights into cell physiologies at different locations inside of a large bioreactor. However, to the best of our knowledge, such metabolic flux analysis techniques have not been fully developed.

\section{MODERN FERMENTATION ENGINEERING: AN INTEGRATED APPROACH FOR BIOFUEL FERMENTATION MANUFACTURING}

The promise of cheap biofuels has yet to be fulfilled. Currently, alcohols (though of a lower energy density) are more promising biofuels than biodiesel/hydrocarbons, as alcohol synthesis pathways are less dependent on the ATP supply and alcohol fermentation can be conducted under anaerobic conditions. Production of biodiesel and hydrocarbon require large amounts of ATP, and their processes are usually restricted to aerobic conditions and their productivities are highly sensitive to the $\mathrm{P} / \mathrm{O}$ ratio (He et al., 2014; Varman et al., 2014). To date, researchers are still unable to create "super bugs" that have both efficient carbon metabolism and frugal energy usage for economical synthesis of advanced biofuels. Thereby, modern fermentation engineering needs to be merged with advanced metabolic engineering to employ the following strategies.

First, it is important to select and develop a proper biofuel chassis with an efficient energy and carbon metabolism. Yeast (e.g., Saccharomyces cerevisiae) is naturally tolerant to alcohols 
and acetate, and it is a robust workhorse for industrial alcohol fermentations. However, the energy metabolism of yeast has a lower net ATP production as additional ATP is consumed during the transport of equivalents of $\mathrm{NADH}$ from the cytoplasm into the mitochondria (Shuler and Kargi, 2002). In addition, the mitochondrial metabolite transport processes may limit the enzyme-substrate accessibility during biofuel synthesis. Thereby, compartmentalization of biosynthetic pathways in yeast's mitochondria is required to improve local enzyme concentrations and microenvironments for biofuel synthesis (Avalos et al., 2013). On the other hand, a bacterial chassis, E. coli, has faster growth and product synthesis rates, pathways that are easier to modify, and a broader capability to co-utilize carbon sources (including xylose). E. coli has already been engineered to produce higher alcohols, biodiesels and other hydrocarbons that demand large amounts of energy molecules. Another promising chassis is microalgae (i.e., cyanobacteria). Although most studies emphasize their photoautotrophic features, photomixotrophic fermentation has two great advantages for industrial use. (1) Photo-fermentations of organic substrates (sugars) can reach high carbon yields of both biofuel and biomass due to mixotrophic $\mathrm{CO}_{2}$ fixation and light energy harvesting to generate ATP and NADPH (You et al., 2014). (2) Photo-fermentation by cyanobacteria has no overflow byproducts and is less susceptible to $\mathrm{CO}_{2}$ /light limitations during the bioprocess scale-up. Another possible direction, non-model species, such as thermophiles, are also promising for cheap biofuel production because such species are particularity suited for consolidated bioprocesses (Lin et al., 2014). Finally, it might be possible to construct a new microbial chassis using a synthetic genome in the near future, which may be developed to contain all the advantageous features of the other microbial hosts. These synthetic or non-model microbes may eventually fulfill the promise of cheap biofuels.

Second, the loss of carbon yield due to ATP/NAD $(\mathrm{P}) \mathrm{H}$ limitations is often severe in engineered microbial hosts. Therefore, modern fermentation engineering should focus on reducing the metabolic burden and enhancing the prosperity of the energy metabolism. There are several effective strategies to improve $\mathrm{NAD}(\mathrm{P}) \mathrm{H}$ and ATP availability. (1) Adding nutrient sources (such as yeast extract) into cell culture; (2) overexpressing NADH dehydrogenase to enhance the respiration efficiency (Calhoun et al., 1993); (3) using engineered enzymes to balance NADH/NADPH generation and consumption (Berrios-Rivera et al., 2002; Javidpour et al., 2014); (4) employing in situ product recovery/separation to avoid culture inhibitions (Baez et al., 2011); and (5) maintaining the optimal cultivation conditions (such as dissolved $\mathrm{O}_{2}$, substrate concentrations, etc.).

Third, traditional fermentation engineering aims to understand bioreactor rheology and bio-reaction kinetics, but there should be a deeper understanding of the microbial host in large bioreactors. Fermentation engineers often study process control parameters such as mixing quality, oxygen/nutrient supply, reactor geometry, impeller selection, aeration rate, heat transfer, power-volume ratio, and the necessary utility operation costs (Delvigne et al., 2005). For example, fermentation engineers have designed fed batch algorithms to avoid acetate secretion by E. coli (Shuler and Kargi, 2002). However, future fermentation engineering should also combine process analyses (including computational fluid dynamics, structured kinetic models, and scale-up simulations) with advanced metabolic flux analysis to capture the cell's behavior and dynamics under the vessel's specific conditions and provide guidelines for process design and control. Systems analysis has been successfully used as a fermentation engineering technique to reveal metabolic bottlenecks, design optimal culture medium, and monitor physiological performance under different bioreactor conditions (Becker et al., 2013; Posch et al., 2013). For example, researchers from Genentech have integrated bioprocess models with metabolic flux analysis to study E. coli metabolism in a $1000 \mathrm{~L}$ bioreactor for the production of a recombinant therapeutic protein. The integrated modeling approach can be used to optimize process variables and media compositions to unlock the optimal cell metabolism for efficient biosynthesis (Meadows et al., 2010). As expected, future fermentation engineering can significantly benefit from combining metabolic flux analysis with mass transport and hydrodynamics to understand cell physiologies in heterogeneous/dynamic bioreactor environments and identify the bioreactor stress factors.

Fourth, synthetic biology offers new opportunities for fermentation scale-up. Introducing synthetic dynamic control systems can prevent the biosynthesis of unnecessary RNAs/proteins/metabolites, increase the efficiencies of energy and carbon usage, and allow a host to adjust its metabolic flux to minimize "maintenance loss" (Zhang et al., 2012). Metabolic pathways can be regulated via transcription factors that quickly respond to shifts in metabolite levels, and thus fluxes in the biosynthetic pathway could be controlled on the time scale of minutes (Holtz and Keasling, 2010). To build dynamic regulatory capability in a microbial host, biosensor-regulators can be used to promote or repress a biofuel pathway or substrate uptake according to its growth conditions (e.g., quorum sensing) or metabolite concentrations (Dunlop et al., 2010). Recently, a dynamic feedback control system was developed that enabled the host to sense metabolic changes by detecting the toxic intermediate's concentration (e.g., malonyl-CoA or acyl-CoA), and thereby controlling the expression of biodiesel synthesis genes (Zhang et al., 2012). Such a feedback control allows cells to maintain the concentration of the precursor and intermediate at desirable levels, and thus both genetic stability and productivity in the new strains were improved. In addition, biosensors of feedforward control, will also be beneficial in the scale-up of fermentations, because they allow cells to respond to environmental changes before a deleterious impact on cell metabolism. For example, $\mathrm{O}_{2}$ limitation leads to acetate secretion and glucose over-consumption during aerobic fermentations. $\mathrm{O}_{2}$ sensitive promoters (Salmon et al., 2003) can be used to control glucose transporter genes and "shut down" glucose uptake when the cells move to $\mathrm{O}_{2}$ limiting zones in a large bioreactor (Figure 3). Although bio-sensing regulatory systems can optimize biomass growth and product synthesis at different growth phases/conditions in laboratory settings, applicability of synthetic biology in scale-up fermentation is still unclear. Recently, the stability of genetic circuits (AND and NOR gate) were evaluated under simulated industrial fermentation conditions, and the circuit's performance (AND gate) deteriorated with 


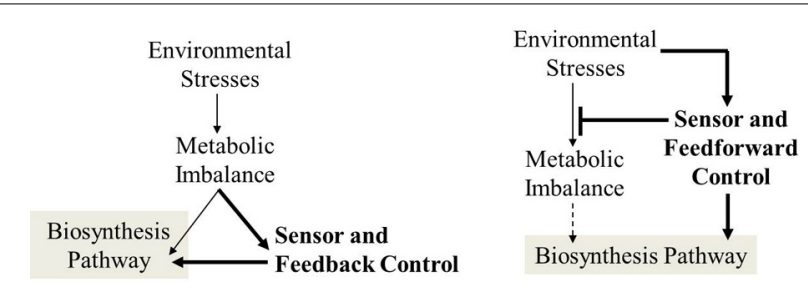

FIGURE 3 | Application of feedback and feedforward sensor-regulator systems to improve cell responses under suboptimal conditions.

increased culture volume (Moser et al., 2012). Thereby, it is necessary for fermentation engineers to test and improve synthetic biology circuits under dynamic and heterogeneous cultivation conditions.

\section{SUMMARY}

Optimization of biofuel fermentation at the industrial scale is difficult and costly. Biofuel fermentation engineering should integrate with metabolic engineering to tune the expression of multiple heterologous genes, improve the energy metabolism (high $\mathrm{P} / \mathrm{O}$ ratio and low cell maintenance), and construct sensor-regulator systems to improve cell productivity in industrial bioreactors. Fermentation engineers should have a comprehensive understanding of both the macroscopic (e.g., oxygen level, mixing, and bioreactor controls) and microscopic (intracellular fluxes) parameters, and thus fill the gaps between laboratory studies and industrial applications. "Scale-down" experiments (large-bioreactor fermentation simulated on small scales) with metabolic flux analysis can be routinely used to diagnose the engineered metabolism, verify synthetic biology circuits, and design optimal fermentation strategies (Figure 2). Most importantly, this broad-scope metabolic knowledge would allow companies to select and focus on "promising" microbial factories with high chances of success.

\section{ACKNOWLEDGMENTS}

We would like to thank Prof. Fuzhong Zhang and William Henson for useful discussions on synthetic biology. This work was supported by the funding from National Science Foundation (MCB0954016).

\section{REFERENCES}

Arakawa, K., and Tomita, M. (2013). "Merging multiple omics datasets in silico: statistical analyses and data interpretation," in Systems Metabolic Engineering, ed H. S. Alper (New York, NY: Humana Press), 459-470.

Atsumi, S., Hanai, T., and Liao, J. C. (2008). Non-fermentative pathways for synthesis of branched-chain higher alcohols as biofuels. Nature 451, 86-89. doi: 10.1038/nature 06450

Atsumi, S., Wu, T.-Y., Eckl, E.-M., Hawkins, S., Buelter, T., and Liao, J. (2010a). Engineering the isobutanol biosynthetic pathway in Escherichia coli by comparison of three aldehyde reductase/alcohol dehydrogenase genes. Appl. Microbiol. Biotechnol. 85, 651-657. doi: 10.1007/s00253-009-2085-6

Atsumi, S., Wu, T.-Y., Machado, I. M. P., Huang, W.-C., Chen, P.-Y., Pellegrini, M., et al. (2010b). Evolution, genomic analysis, and reconstruction of isobutanol tolerance in Escherichia coli. Mol. Syst. Biol. 6:449. doi: 10.1038/msb.2010.98

Avalos, J. L., Fink, G. R., and Stephanopoulos, G. (2013). Compartmentalization of metabolic pathways in yeast mitochondria improves the production of branched-chain alcohols. Nat. Biotechnol. 31, 335-341. doi: 10.1038/ nbt. 2509

Baez, A., Cho, K.-M., and Liao, J. (2011). High-flux isobutanol production using engineered Escherichia coli: a bioreactor study with in situ product removal. Appl. Microbiol. Biotechnol. 90, 1681-1690. doi: 10.1007/s00253-011-3173-y

Becker, J., Reinefeld, J., Stellmacher, R., Schäfer, R., Lange, A., Meyer, H., et al. (2013). Systems-wide analysis and engineering of metabolic pathway fluxes in bio-succinate producing Basfia succiniciproducens. Biotechnol. Bioeng. 110, 3013-3023. doi: 10.1002/bit.24963

Berrıos-Rivera, S. J., Bennett, G. N., and San, K.-Y. (2002). Metabolic engineering of Escherichia coli: increase of NADH availability by overexpressing an $\mathrm{NAD}^{+}$-dependent formate dehydrogenase. Metab. Eng. 4, 217-229. doi: 10.1006/mben.2002.0227

Blanch, H. W., and Clark, D. S. (1997). Biochemical Engineering. New York, NY: Marcel Dekker Inc.

Bogorad, I. W., Lin, T.-S., and Liao, J. C. (2013). Synthetic non-oxidative glycolysis enables complete carbon conservation. Nature 502, 693-697. doi: 10.1038 /nature 12575

Bylund, F., Castan, A., Mikkola, R., Veide, A., and Larsson, G. (2000). Influence of scale-up on the quality of recombinant human growth hormone. Biotechnol. Bioeng. 69, 119-128. doi: 10.1002/(SICI)1097-0290(20000720)69:2<119::AIDBIT1 > 3.0.CO;2-9

Bylund, F., Collet, E., Enfors, S. O., and Larsson, G. (1998). Substrate gradient formation in the large-scale bioreactor lowers cell yield and increases by-product formation. Bioprocess Eng. 18, 171-180. doi: 10.1007/s004490050427

Calhoun, M. W., Oden, K. L., Gennis, R. B., De Mattos, M. J., and Neijssel, O. M. (1993). Energetic efficiency of Escherichia coli: effects of mutations in components of the aerobic respiratory chain. J. Bacteriol. 175, 3020-3025.

Carneiro, S., Ferreira, E. C., and Rocha, I. (2013). Metabolic responses to recombinant bioprocesses in Escherichia coli. J. Biotechnol. 164, 396-408. doi: 10.1016/j.jbiotec.2012.08.026

Carrier, T., Jones, K. L., and Keasling, J. D. (1998). mRNA stability and plasmid copy number effects on gene expression from an inducible promoter system. Biotechnol. Bioeng. 59, 666-672.

Chang, M. C. Y., Eachus, R. A., Trieu, W., Ro, D.-K., and Keasling, J. D. (2007). Engineering Escherichia coli for production of functionalized terpenoids using plant P450s. Nat. Chem. Biol. 3, 274-277. doi: 10.1038/nchembio875

Choi, Y. J., and Lee, S. Y. (2013). Microbial production of short-chain alkanes. Nature 502, 571-574. doi: 10.1038/nature12536

Choi, Y. J., Park, J. H., Kim, T., and Lee, S. Y. (2012). Metabolic engineering of Escherichia coli for the production of 1-propanol. Metab. Eng. 14, 477-486. doi: 10.1016/j.ymben.2012.07.006

Chubukov, V., Uhr, M., Le Chat, L., Kleijn, R. J., Jules, M., Link, H., et al. (2013). Transcriptional regulation is insufficient to explain substrate-induced flux changes in Bacillus subtilis. Mol. Syst. Biol. 9:709. doi: 10.1038/msb.2013.66

Colletti, P. F., Goyal, Y., Varman, A. M., Feng, X., Wu, B., and Tang, Y. J. (2011). Evaluating factors that influence microbial synthesis yields by linear regression with numerical and ordinal variables. Biotechnol. Bioeng. 108, 893-901. doi: 10.1002/bit.22996

Conrado, R. J., and Gonzalez, R. (2014). Envisioning the bioconversion of methane to liquid fuels. Science 343, 621-623. doi: 10.1126/science.1246929

Delvigne, F., Mejdoub, T., Destain, J., Delroisse, J.-M., Vandenbol, M., Haubruge, E., et al. (2005). "Estimation of bioreactor efficiency through structured hydrodynamic modeling case study of a Pichia pastoris fed-batch process," in TwentySixth Symposium on Biotechnology for Fuels and Chemicals, eds B. Davison, B. Evans, M. Finkelstein, and J. McMillan (New York, NY: Humana Press), 653-671.

Dueber, J. E., Wu, G. C., Malmirchegini, G. R., Moon, T. S., Petzold, C. J., Ullal, A. V., et al. (2009). Synthetic protein scaffolds provide modular control over metabolic flux. Nat. Biotechnol. 27, 753-759. doi: 10.1038/nbt.1557

Dunlop, M., Keasling, J., and Mukhopadhyay, A. (2010). A model for improving microbial biofuel production using a synthetic feedback loop. Syst. Synth. Biol. 4, 95-104. doi: 10.1007/s11693-010-9052-5

Edwards, J. S., Ibarra, R. U., and Palsson, B. O. (2001). In silico predictions of Escherichia coli metabolic capabilities are consistent with experimental data. Nat. Biotechnol. 19, 125-130. doi: 10.1038/84379

Enfors, S. O., Jahic, M., Rozkov, A., Xu, B., Hecker, M., Jürgen, B., et al. (2001). Physiological responses to mixing in large scale bioreactors. J. Biotechnol. 85, 175-185. doi: 10.1016/S0168-1656(00)00365-5 
Gorochowski, T. E., van den Berg, E., Kerkman, R., Roubos, J. A., and Bovenberg, R. A. L. (2013). Using synthetic biological parts and microbioreactors to explore the protein expression characteristics of Escherichia coli. ACS Synth. Biol. 3, 129-139. doi: 10.1021/sb4001245

Gygi, S. P., Rochon, Y., Franza, B. R., and Aebersold, R. (1999). Correlation between protein and mRNA abundance in yeast. Mol. Cell. Biol. 19, 1720-1730.

He, L., Xiao, Y., Gebreselassie, N., Zhang, F., Antoniewicz, M. R., Tang, Y. J., et al. (2014). Central metabolic responses to the overproduction of fatty acids in Escherichia coli based on ${ }^{13} \mathrm{C}$-metabolic flux analysis. Biotechnol. Bioeng. 111, 575-585. doi: 10.1002/bit.25124

Hermann, T. (2003). Industrial production of amino acids by coryneform bacteria. J. Biotechnol. 104, 155-172. doi: 10.1016/S0168-1656(03)00149-4

Hoehler, T. M., and Jorgensen, B. B. (2013). Microbial life under extreme energy limitation. Nat. Rev. Microbiol. 11, 83-94. doi: 10.1038/nrmicro2939

Holtz, W. J., and Keasling, J. D. (2010). Engineering static and dynamic control of synthetic pathways. Cell 140, 19-23. doi: 10.1016/j.cell.2009.12.029

Javidpour, P., Pereira, J. H., Goh, E.-B., McAndrew, R. P., Ma, S. M., Friedland, G. D., et al. (2014). Biochemical and structural studies of NADH-dependent FabG used to increase the bacterial production of fatty acids under anaerobic conditions. Appl. Environ. Microbiol. 80, 497-505. doi: 10.1128/AEM. 03194-13

Jiang, W., Bikard, D., Cox, D., Zhang, F., and Marraffini, L. A. (2013). RNA-guided editing of bacterial genomes using CRISPR-Cas systems. Nat. Biotechnol. 31, 233-239. doi: 10.1038/nbt.2508

Jones, K. L., Kim, S.-W., and Keasling, J. D. (2000). Low-copy plasmids can perform as well as or better than high-copy plasmids for metabolic engineering of bacteria. Metab. Eng. 2, 328-338. doi: 10.1006/mben.2000.0161

Kalscheuer, R., Stölting, T., and Steinbüchel, A. (2006). Microdiesel: Escherichia coli engineered for fuel production. Microbiology 152, 2529-2536. doi: 10.1099/mic.0.29028-0

Khalil, A. S., and Collins, J. J. (2010). Synthetic biology: applications come of age. Nat. Rev. Genet. 11, 367-379. doi: 10.1038/nrg2775

Kind, S., Becker, J., and Wittmann, C. (2013). Increased lysine production by flux coupling of the tricarboxylic acid cycle and the lysine biosynthetic pathwaymetabolic engineering of the availability of succinyl-CoA in Corynebacterium glutamicum. Metab. Eng. 15, 184-195. doi: 10.1016/j.ymben.2012.07.005

Lamonica, M. (2014). Why the Promise of Cheap Fuel from Super Bugs Fell Short? Cambridge, MA: MIT Technology Review.

Lan, E. I., and Liao, J. C. (2012). ATP drives direct photosynthetic production of 1-butanol in cyanobacteria. Proc. Natl. Acad. Sci. U.S.A. 109, 6018-6023. doi: 10.1073/pnas.1200074109

Lin, P. P., Rabe, K. S., Takasumi, J. L., Kadisch, M., Arnold, F. H., and Liao, J. C. (2014). Isobutanol production at elevated temperatures in thermophilic Geobacillus thermoglucosidasius. Metab. Eng. 24, 1-8. doi: 10.1016/j.ymben.2014.03.006

Lindberg, P., Park, S., and Melis, A. (2010). Engineering a platform for photosynthetic isoprene production in cyanobacteria, using Synechocystis as the model organism. Metab. Eng. 12, 70-79. doi: 10.1016/j.ymben.2009.10.001

Liu, L., Yang, T., Ji, J., Wen, Q., Morgan, A., Jin, B., et al. (2013). Integrating multiple 'omics' analyses identifies serological protein biomarkers for preeclampsia. BMC Med. 11:236. doi: 10.1186/1741-7015-11-236

Mandy, D. E., Goldford, J. E., Yang, H., Allen, D. K., and Libourel, I. G. L. (2014). Metabolic flux analysis using ${ }^{13} \mathrm{C}$ peptide label measurements. Plant J. 77, 476-486. doi: 10.1111/tpj.12390

Meadows, A. L., Karnik, R., Lam, H., Forestell, S., and Snedecor, B. (2010). Application of dynamic flux balance analysis to an industrial Escherichia coli fermentation. Metab. Eng. 12, 150-160. doi: 10.1016/j.ymben.2009.07.006

Moser, F., Broers, N. J., Hartmans, S., Tamsir, A., Kerkman, R., Roubos, J. A., et al. (2012). Genetic circuit performance under conditions relevant for industrial bioreactors. ACS Synth. Biol. 1, 555-564. doi: 10.1021/sb3000832

Nakamura, C. E., and Whited, G. M. (2003). Metabolic engineering for the microbial production of 1,3-propanediol. Curr. Opin. Biotechnol. 14, 454-459. doi: 10.1016/j.copbio.2003.08.005

Neupert, J., Karcher, D., and Bock, R. (2008). Design of simple synthetic RNA thermometers for temperature-controlled gene expression in Escherichia coli. Nucleic Acids Res. 36:e124. doi: 10.1093/nar/gkn545

Nielsen, J., Fussenegger, M., Keasling, J., Lee, S. Y., Liao, J. C., Prather, K., et al. (2014). Engineering synergy in biotechnology. Nat. Chem. Biol. 10, 319-322. doi: $10.1038 /$ nchembio. 1519
Nowroozi, F., Baidoo, E. K., Ermakov, S., Redding-Johanson, A., Batth, T., Petzold, C., et al. (2014). Metabolic pathway optimization using ribosome binding site variants and combinatorial gene assembly. Appl. Microbiol. Biotechnol. 98, 1567-1581. doi: 10.1007/s00253-013-5361-4

Oliver, J. W., Machado, I. M., Yoneda, H., and Atsumi, S. (2013). Cyanobacterial conversion of carbon dioxide to 2,3-butanediol. Proc. Natl. Acad. Sci. U.S.A. 110, 1249-1254. doi: 10.1073/pnas.1213024110

Orth, J. D., Thiele, I., and Palsson, B. O. (2010). What is flux balance analysis? Nat. Biotechnol. 28, 245-248. doi: 10.1038/nbt.1614

Ow, D. S.-W., Lee, D.-Y., Yap, M. G.-S., and Oh, S. K.-W. (2009). Identification of cellular objective for elucidating the physiological state of plasmid-bearing Escherichia coli using genome-scale in silico analysis. Biotechnol. Prog. 25, 61-67. doi: 10.1002/btpr.51

Park, J. H., Lee, S. Y., Kim, T. Y., and Kim, H. U. (2008). Application of systems biology for bioprocess development. Trends Biotechnol. 26, 404-412. doi: 10.1016/j.tibtech.2008.05.001

Peralta-Yahya, P. P., Zhang, F., Del Cardayre, S. B., and Keasling, J. D. (2012). Microbial engineering for the production of advanced biofuels. Nature 488, 320-328. doi: 10.1038/nature11478

Pham, T. K., Chong, P. K., Gan, C. S., and Wright, P. C. (2006). Proteomic analysis of Saccharomyces cerevisiae under high gravity fermentation conditions. J. Proteome Res. 5, 3411-3419. doi: 10.1021/pr060377p

Posch, A. E., Herwig, C., and Spadiut, O. (2013). Science-based bioprocess design for filamentous fungi. Trends Biotechnol. 31, 37-44. doi: 10.1016/j.tibtech.2012.10.008

Poust, S., Hagen, A., Katz, L., and Keasling, J. D. (2014). Narrowing the gap between the promise and reality of polyketide synthases as a synthetic biology platform. Curr. Opin. Biotechnol. 30, 32-39. doi: 10.1016/j.copbio.2014. 04.011

Pratt, A. J., and MacRae, I. J. (2009). The RNA-induced silencing complex: a versatile gene-silencing machine. J. Biol. Chem. 284, 17897-17901. doi: 10.1074/jbc.R900012200

Redding-Johanson, A. M., Batth, T. S., Chan, R., Krupa, R., Szmidt, H. L., Adams, P. D., et al. (2011). Targeted proteomics for metabolic pathway optimization: application to terpene production. Metab. Eng. 13, 194-203. doi: 10.1016/j.ymben.2010.12.005

Rude, M. A., and Schirmer, A. (2009). New microbial fuels: a biotech perspective. Curr. Opin. Microbiol. 12, 274-281. doi: 10.1016/j.mib.2009.04.004

Rühl, M., Hardt, W. D., and Sauer, U. (2011). Subpopulation-specific metabolic pathway usage in mixed cultures as revealed by reporter protein-based ${ }^{13} \mathrm{C}$ analysis. Appl. Environ. Microbiol. 77, 1816-1821. doi: 10.1128/AEM. 02696-10

Rühl, M., Zamboni, N., and Sauer, U. (2010). Dynamic flux responses in riboflavin overproducing Bacillus subtilis to increasing glucose limitation in fed-batch culture. Biotechnol. Bioeng. 105, 795-804. doi: 10.1002/bit.22591

Salmon, K., Hung, S.-P., Mekjian, K., Baldi, P., Hatfield, G. W., and Gunsalus, R. P. (2003). Global gene expression profiling in Escherichia coli K12: the effects of oxygen availability and FNR. J. Biol. Chem. 278, 29837-29855. doi: 10.1074/jbc.M213060200

Sauer, U. (2006). Metabolic networks in motion: ${ }^{13} \mathrm{C}$-based flux analysis. Mol. Syst. Biol. 2:62. doi: 10.1038/msb4100109

Sauer, U., and Bailey, J. E. (1999). Estimation of P-to-O ratio in Bacillus subtilis and its influence on maximum riboflavin yield. Biotechnol. Bioeng. 64, 750-754.

Schwab, W. (2003). Metabolome diversity: too few genes, too many metabolites? Phytochemistry 62, 837-849. doi: 10.1016/S0031-9422(02)00723-9

Shaikh, A. S., Tang, Y. J., Mukhopadhyay, A., and Keasling, J. D. (2008). Isotopomer distributions in amino acids from a highly expressed protein as a proxy for those from total protein. Anal. Chem. 80 886-890. doi: 10.1021/ac071445+

Shuler, M. L., and Kargi, F. (2002). Bioprocess Engineering. Upper Saddle River, NJ: Prentice Hall.

Soma, Y., Tsuruno, K., Wada, M., Yokota, A., and Hanai, T. (2014). Metabolic flux redirection from a central metabolic pathway toward a synthetic pathway using a metabolic toggle switch. Metab. Eng. 23, 175-184. doi: 10.1016/j.ymben.2014.02.008

Steen, E. J., Kang, Y., Bokinsky, G., Hu, Z., Schirmer, A., McClure, A., et al. (2010). Microbial production of fatty-acid-derived fuels and chemicals from plant biomass. Nature 463, 559-562. doi: 10.1038/nature08721

Stephanopoulos, G., Aristidou, A., and Nielsen, J. (1998). Metabolic Engineering: Principles and Methodologies. San Diego, CA: Academic Press. 
Sun, N., and Zhao, H. (2013). Transcription activator-like effector nucleases (TALENs): a highly efficient and versatile tool for genome editing. Biotechnol. Bioeng. 110, 1811-1821. doi: 10.1002/bit.24890

Tang, Y. J., Martin, H. G., Myers, S., Rodriguez, S., Baidoo, E. K., and Keasling, J. D. (2009). Advances in analysis of microbial metabolic fluxes via ${ }^{13} \mathrm{C}$ isotopic labeling. Mass Spectrom. Rev. 28, 362-375. doi: 10.1002/mas.20191

Topp, S., Reynoso, C. M. K., Seeliger, J. C., Goldlust, I. S., Desai, S. K., Murat, D., et al. (2010). Synthetic riboswitches that induce gene expression in diverse bacterial species. Appl. Environ. Microbiol. 76, 7881-7884. doi: 10.1128/AEM.01537-10

Varma, A., and Palsson, B. O. (1994). Stoichiometric flux balance models quantitatively predict growth and metabolic by-product secretion in wild-type Escherichia coli W3110. Appl. Environ. Microbiol. 60, 3724-3731.

Varman, A., He, L., You, L., Hollinshead, W., and Tang, Y. (2014). Elucidation of intrinsic biosynthesis yields using ${ }^{13} \mathrm{C}$-based metabolism analysis. Microb. Cell Fact. 13, 42. doi: 10.1186/1475-2859-13-42

Way, J. C., Collins, J. J., Keasling, J. D., and Silver, P. A. (2014). Integrating biological redesign: where synthetic biology came from and where it needs to go. Cell 157, 151-161. doi: 10.1016/j.cell.2014.02.039

Withers, S. T., Gottlieb, S. S., Lieu, B., Newman, J. D., and Keasling, J. D. (2007). Identification of isopentenol biosynthetic genes from Bacillus subtilis by a screening method based on isoprenoid precursor toxicity. Appl. Environ. Microbiol. 73, 6277-6283. doi: 10.1128/AEM.00861-07

Yoon, S., Han, M.-J., Jeong, H., Lee, C., Xia, X.-X., Lee, D.-H., et al. (2012). Comparative multi-omics systems analysis of Escherichia coli strains B and K-12. Genome Biol. 13, R37. doi: 10.1186/gb-2012-13-5-r37

You, L., Berla, B., He, L., Pakrasi, H. B., and Tang, Y. J. (2014). ${ }^{13}$ C-MFA delineates the photomixotrophic metabolism of Synechocystis sp. PCC 6803 under light- and carbon-sufficient conditions. Biotechnol. J. 9, 684-692. doi: 10.1002/biot.201300477

Zhang, F. Z., Carothers, J. M., and Keasling, J. D. (2012). Design of a dynamic sensor-regulator system for production of chemicals and fuels derived from fatty acids. Nat. Biotechnol. 30, 354- 359. doi: 10.1038/nbt.2149

Zhang, W., Li, F., and Nie, L. (2010). Integrating multiple 'omics' analysis for microbial biology: application and methodologies. Microbiology 156, 287-301. doi: 10.1099/mic.0.034793-0

Zhang, Y. H. P. (2009). A sweet out-of-the-box solution to the hydrogen economy: is the sugar-powered car science fiction? Energy Environ. Sci. 2, 272-282. doi: $10.1039 / \mathrm{b} 818694 \mathrm{~d}$

Conflict of Interest Statement: The authors declare that the research was conducted in the absence of any commercial or financial relationships that could be construed as a potential conflict of interest.

Received: 18 March 2014; accepted: 20 June 2014; published online: 09 July 2014. Citation: Hollinshead W, He L and Tang YJ (2014) Biofuel production: an odyssey from metabolic engineering to fermentation scale-up. Front. Microbiol. 5:344. doi: 10.3389/ fmicb.2014.00344

This article was submitted to Microbial Physiology and Metabolism, a section of the journal Frontiers in Microbiology.

Copyright (c) 2014 Hollinshead, He and Tang. This is an open-access article distributed under the terms of the Creative Commons Attribution License (CC BY). The use, distribution or reproduction in other forums is permitted, provided the original author(s) or licensor are credited and that the original publication in this journal is cited, in accordance with accepted academic practice. No use, distribution or reproduction is permitted which does not comply with these terms. 